\title{
Dynamics and chemistry of vortex remnants in late Arctic spring 1997 and 2000: Simulations with the Chemical Lagrangian Model of the Stratosphere (CLaMS)
}

\author{
P. Konopka ${ }^{1}$, J.-U. Grooß ${ }^{1}$, S. Bausch ${ }^{1}$, R. Müller ${ }^{1}$, D. S. McKenna ${ }^{2}$, O. Morgenstern ${ }^{3}$, and Y. Orsolini ${ }^{4}$ \\ ${ }^{1}$ Institute for Stratospheric Chemistry (ICG-I), 52425 Jülich, Germany \\ ${ }^{2}$ National Center for Atmospheric Research, Boulder, CO, USA \\ ${ }^{3}$ Max-Planck-Institut für Meteorologie, Hamburg, Germany \\ ${ }^{4}$ Norwegian Institute for Air Research (NILU), Kjeller, Norway
}

Received: 30 December 2002 - Published in Atmos. Chem. Phys. Discuss.: 25 February 2003

Revised: 4 June 2003 - Accepted: 16 June 2003 - Published: 23 June 2003

\begin{abstract}
High-resolution simulations of the chemical composition of the Arctic stratosphere during late spring 1997 and 2000 were performed with the Chemical Lagrangian Model of the Stratosphere (CLaMS). The simulations were performed for the entire northern hemisphere on two isentropic levels $450 \mathrm{~K}(\approx 18 \mathrm{~km})$ and $585 \mathrm{~K}(\approx 24 \mathrm{~km})$.

The spatial distribution and the lifetime of the vortex remnants formed after the vortex breakup in May 1997 display different behavior above and below $20 \mathrm{~km}$. Above $20 \mathrm{~km}$, vortex remnants propagate southward (up to $40^{\circ} \mathrm{N}$ ) and are "frozen in" in the summer circulation without significant mixing. Below $20 \mathrm{~km}$ the southward propagation of the remnants is bounded by the subtropical jet. Their lifetime is shorter by a factor of 2 than that above $20 \mathrm{~km}$, owing to significant stirring below this altitude. The behavior of vortex remnants formed in March 2000 is similar but, due to an earlier vortex breakup, dominated during the first 6 weeks after the vortex breakup by westerly winds, even above $20 \mathrm{~km}$.

Vortex remnants formed in May 1997 are characterized by large mixing ratios of $\mathrm{HCl}$ indicating negligible, halogeninduced ozone loss. In contrast, mid-latitude ozone loss in late boreal spring 2000 is dominated, until mid-April, by halogen-induced ozone destruction within the vortex remnants, and subsequent transport of the ozone-depleted polar air masses (dilution) into the mid-latitudes. By varying the intensity of mixing in CLaMS, the impact of mixing on the formation of $\mathrm{ClONO}_{2}$ and ozone depletion is investigated. We find that the photochemical decomposition of $\mathrm{HNO}_{3}$ and not mixing with $\mathrm{NO}_{x}$-rich mid-latitude air is the main source of $\mathrm{NO}_{x}$ within the vortex remnants in March and April 2000. Ozone depletion in the remnants is driven by $\mathrm{ClO}_{x}$ photolytically formed from $\mathrm{ClONO}_{2}$. At the end of May 1997, the halogen-induced ozone deficit at $450 \mathrm{~K}$ poleward of $30^{\circ} \mathrm{N}$
\end{abstract}

Correspondence to: P. Konopka

(p.konopka@fz-juelich.de) amounts to $\approx 12 \%$ with $\approx 10 \%$ in the polar vortex and $\approx 2 \%$ in well-isolated vortex remnants after the vortex breakup.

\section{Introduction}

Long-term ground-based measurements over Europe show that the total column of ozone began to decline in the 1970s. The decrease was greatest in the winter/spring period, with the ozone decline trend in the late 1990s being around 3$6 \% /$ decade. The main contribution is located in the $12-20 \mathrm{~km}$ altitude range (WMO, 1998).

One of the widely discussed mechanisms contributing to this trend is the ozone depletion in the Arctic vortex and its impact on the mid-latitudes. During winter and spring, chlorine in the polar vortex is activated on the surface of polar stratospheric clouds and causes severe ozone destruction (WMO, 1998). Knudsen and Grooß (2000) estimated from calculations done for 1995 and 1997 that approximately $40 \%$ of the observed TOMS total ozone trends result from transport of the ozone-depleted vortex air into the mid-latitudes. By applying this method north of $63^{\circ}$ for the period 1992 2000, Andersen and Knudsen (2002) deduced that the major part $(75 \%)$ of the observed Arctic ozone decrease in March and most of the variability may be explained by winter/spring ozone depletion in the polar vortex. On the other hand, using 3-D CTM studies Chipperfield and Jones (1999) showed that during the 1990s the dynamic variations dominated the interannual variability of ozone north of $63^{\circ}$ with little evidence of a trend towards more wintertime chemical depletion.

The first studies considering the details of the transport of the vortex air into the mid-latitudes were based on LIMS data (LIMS - Limb Infrared Monitor of the Stratosphere) and GCM simulations. Hess (1991) found that long-lived anomalies of tracers were still observed two months after 
the breakup of the polar vortex in spring 1979. Using the PDF technique for 3-D simulations of $\mathrm{N}_{2} \mathrm{O}$, Orsolini (2001) identified some long-lived westward-propagating tracer patterns in the 1998 summer polar stratosphere above $20 \mathrm{~km}$ that resulted from the slow advection of coarsely-mixed vortex remnants. Based on 3-D CTM simulations with a parameterized ozone chemistry, Piani et al. (2002) showed that by the end of June, 2000, above $420 \mathrm{~K}$, much of the ozone-depleted air was transported from the polar regions to the subtropics, whereas below $420 \mathrm{~K}$, these air masses remained polarward of $\approx 55^{\circ} \mathrm{N}$. They suggested that below $420 \mathrm{~K}$ the subtropical jet provides an effective transport barrier while stirring after the breakup of the polar vortex is important at upper levels.

Despite these achievements, questions concerning the lifetime, the spatial distribution, and the year-to-year variability of such remnants are still open. Also their impact on the total ozone column, in particular over the densely populated regions in northern mid-latitudes, needs to be quantified. Furthermore, only few studies exist that discuss the effect of stirring and mixing on the ozone chemistry in the slowly diluting vortex remnants (Marchand et al., 2003).

Inaccurate representation of mixing in photochemical transport models may influence the predictions of stratospheric ozone depletion (Edouard et al., 1996; Searle et al., 1998a,b). Satellite observations (Riese et al., 1999), in situ measurements (Tuck, 1989), and dynamical model studies based on such experiments (e.g. Plumb et al., 1994; Waugh et al., 1997; Orsolini et al., 1997; Balluch and Haynes, 1997) demonstrated the existence of filamentary structures on a broad range of spatial scales in stratospheric chemical tracer fields. Chemical transport models that do not resolve filamentary structures and do not represent their dissipation times realistically will not simulate non-linear chemical reactions accurately. Using a photochemical box model to study the impact of mixing on the deactivation of stratospheric chlorine, Tan et al. (1998) showed that both box models without mixing and the currently employed grid-based numerical models can, in certain circumstances, significantly over- and underestimate the observed ozone loss rates. Furthermore, based on idealized isentropic simulations, they concluded that a spatial resolution better than $40 \mathrm{~km}$ is necessary to obtain a correct description of ozone loss that is not sensitive to the numerical diffusivity of the model.

To study the impact of transport on the spatial distribution, the lifetime, and the ozone chemistry in the vortex remnants in spring/summer 1997 and 2000, we use the high-resolution, isentropic (2-D) version of the Chemical Lagrangian Model of the Stratosphere (CLaMS) (McKenna et al., 2002,a). We chose these two periods because of their completely different characteristics with respect to the lifetime of the Arctic polar vortex: Whereas the vortex in 1997 was extremely long-lived with the final breakup around mid-May (Coy et al., 1997), the vortex decay in mid-March 2000 is more typical for the final warmings observed in the last twenty years (Manney and Sabutis, 2000).
The Lagrangian view of transport allows mixing to be described in its own way. Mixing in CLaMS is induced by an adaptive regridding of the (isentropic) air parcels (APs) with mean distance to the next neighbors given by $r_{0}$ (model resolution). The regridding procedure is applied after each advection time step $\Delta t$ (6-24 hours) that is conducted in terms of isentropic (2-D) trajectories. The mixing intensity is driven by the horizontal deformations in the flow measured by the finite time Lyapunov exponent $\lambda$. Significant mixing occurs only in flow regions where $\lambda$ exceeds a prescribed critical value $\lambda_{c}$. In contrast, in the Eulerian approach the numerical diffusion is present always and everywhere due to the high frequency of interpolations of fluid elements on the fixed spatial grid (Courant criterion), the contribution of the CLaMS regridding procedure to the transport can be contolled. It can be continuously reduced (e.g. by increasing the critical Lyapunov exponent $\lambda_{c}$ ) until tracers are solely transported along trajectories without any mass exchange between the APs. We call this (reversible) part of transport pure advection. The regridding procedure is controlled by the critical Lyapunov exponent $\lambda_{c}$, the model resolution $r_{0}$, and the length of the advection time step $\Delta t$ (or the grid adaptation frequency $1 / \Delta t$ ). These parameters define the (irreversible) part of transport, i.e. mixing.

The paper is organized as follows. In Sect. 2 we describe the model configuration and justify the isentropic approximation by comparing the $\mathrm{CLaMS} \mathrm{CH}_{4}$ distributions with HALOE observations. Section 3 discusses the spatial distribution and the lifetime of the vortex remnants observed in spring and summer 1997 and 2000. In Sect. 4, the ozone chemistry occurring in these remnants is considered. The impact of mixing on the chlorine deactivation and the ozone loss is discussed in Sect. 5. Finally, conclusions are drawn in Sect. 6.

\section{Simulations with CLaMS}

Isentropic CLaMS studies are carried out for two periods: 10.04-31.07 1997 and 10.2-01.06 2000, at the two isentropic levels 450 and $585 \mathrm{~K}$. The meteorological fields are taken from ECMWF data. As a reference case, we employ a (quasiuniform) distribution of APs over the northern hemisphere with the distance between the neighboring APs $r_{0}=65 \mathrm{~km}$ and $r_{0}=200 \mathrm{~km}$ north- and southward of $30^{\circ} \mathrm{N}$, respectively. The critical Lyapunov exponent $\lambda_{c}$ and the time step $\Delta t$ are set to $1.2 \mathrm{day}^{-1}$ and 24 hours, respectively. In the following, we call this configuration of mixing parameters adjusted or optimal mixing. The optimal mixing leads to the best agreement between the CLaMS simulations and the in situ aircraft measurements of tracers observed at the edge of the northern polar vortex during the SOLVE/THESEO-2000 campaign (Konopka et al., 2003). The combinations of the mixing parameters can be quantified by the so-called effective diffusivity (perpendicular to the wind direction) given as 
$D \approx r_{0}^{2} /(4 \Delta t) \exp \left(-2 \lambda_{c} \Delta t\right)$ (McKenna et al. (2002) use the notation $D_{-}^{c}$ for the effective diffusivity $D$ discussed here). For the optimal mixing $D$ amounts to $1.110^{3} \mathrm{~m}^{2} \mathrm{~s}^{-1}$ northward of $30^{\circ} \mathrm{N}$.

In addition, to study the influence of mixing on chemistry, we consider distributions of APs with spatial resolutions $r_{0}=100,200$ and $400 \mathrm{~km}$ northward of $30^{\circ} \mathrm{N}$. The strongest impact on mixing can be achieved by varying the spatial resolution due to the quadratic dependence of the effective diffusivity on $r_{0}$. Thus, the corresponding effective diffusivities are $2.610^{3}, 1.110^{5}$ and $4.210^{5} \mathrm{~m}^{2} \mathrm{~s}^{-1}$. The CLaMS transport scheme resolves horizontal structures up to the order of $r_{0} \exp \left(-\lambda_{c} \Delta t\right)$, i.e. for $r_{0}=65 \mathrm{~km}$ the smallest resolved scales are approximately $20 \mathrm{~km}$.

The initial distribution of all chemical species on 10.04.1997 is derived from MLS and HALOE observations using trajectory mapping, tracer/tracer and tracer/equivalent latitude correlations. In addition, ER-2, POAM and TRIPLE observations are taken into account for the initialization at 10.02.2000. The remaining species are initialized from a 2D model climatology. The denitrification in 1997 is derived from the MLS data, whereas a one-month temperature history is used to parameterize the sedimentation of NAT and ice particles and the subsequent effect of $\mathrm{HNO}_{3}$ and $\mathrm{H}_{2} \mathrm{O}$ removal (Grooß et al., 2002; Konopka et al., 2003).

In Fig. 1 the isentropic CLaMS distributions of $\mathrm{CH}_{4}$ at 450 and $585 \mathrm{~K}$ about 12 days after the vortex breakup in 1997 are shown. For comparison HALOE observations are overlaid (circles). Vortex remnants at $450 \mathrm{~K}$ are more strongly bounded around the pole and are mixed more intensively than the remnants at $585 \mathrm{~K}$.

Before we quantify these properties more precisely, some remarks on the validity of the isentropic calculations are necessary. The isentropic approximation is motivated by weak diabatic descent of the vortex air at both levels between midFebruary and the end of May. Diabatic descent rates derived from the radiation module (Zhong and Haigh, 1995) based on the Morcrette scheme (Morcrette, 1991) show that during the period under consideration, the vortex air masses do not significantly change their potential temperatures in the $\theta$-range between 400 and $600 \mathrm{~K}(\Delta \theta<30 \mathrm{~K})$.

Aditionally, we verify the quality of the CLaMS transport by comparing the simulated distributions of $\mathrm{CH}_{4}$ with the HALOE observations. Figure 2 shows the results of such comparison for two CLaMS configurations: without mixing (i.e. transport only in terms of forward trajectories) and with the optimal mixing. The correlation coefficient $\rho$ between the observed and simulated mixing ratios (see legend in Fig. 2) show that the CLaMS simulation with optimal mixing reproduces fairly well the $\mathrm{CH}_{4}$ distributions observed by HALOE in spring and summer 1997 northward of $30^{\circ}$ N. Furthermore, the CLaMS mixing scheme smoothes out some of the very low $\mathrm{CH}_{4}$ mixing ratios present in the pure advection transport that are not observed by HALOE (in partic-
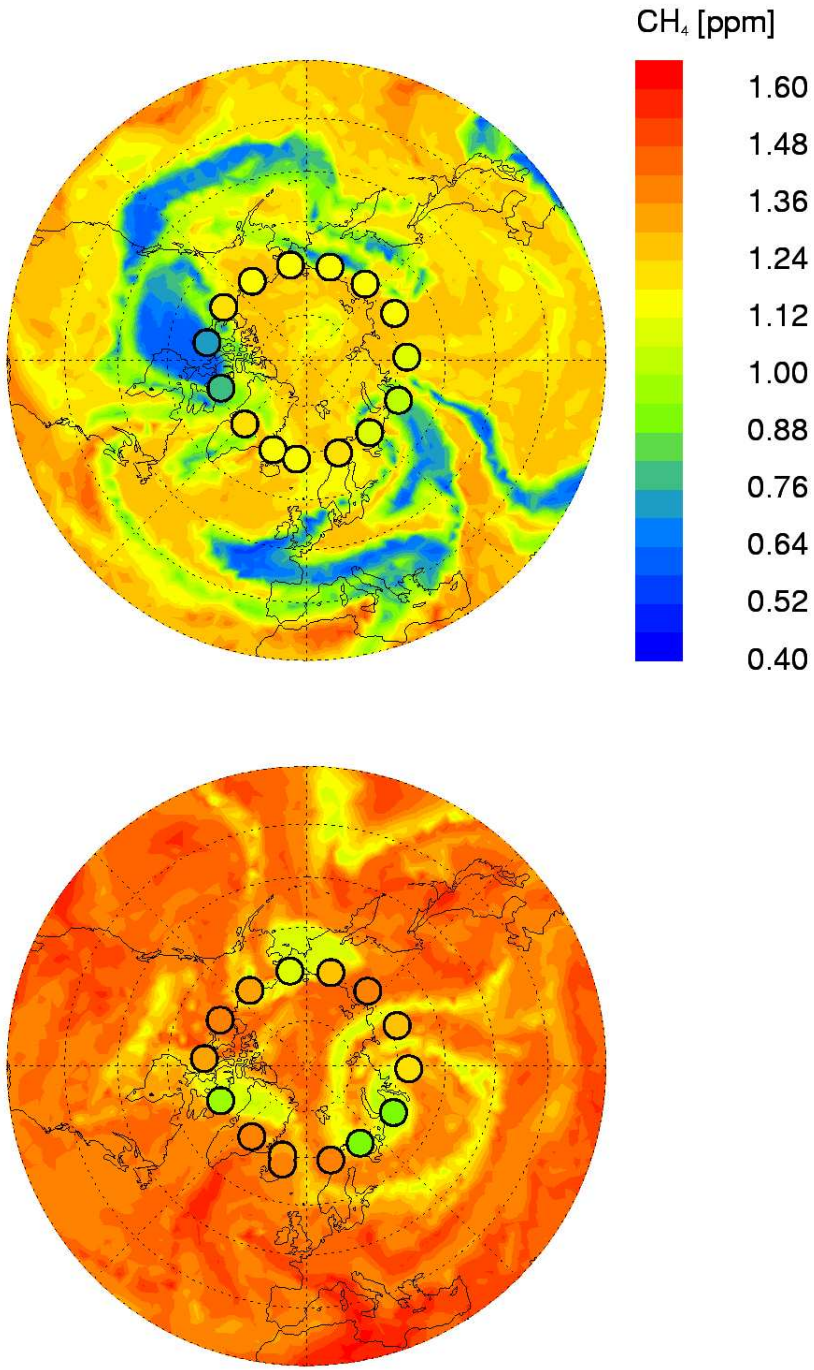

Fig. 1. $\mathrm{CH}_{4}$ simulated with CLaMS at $\theta=585 \mathrm{~K}$ (top) and $450 \mathrm{~K}$ (bottom) at 22.05.1997, i.e. about 12 days after the vortex breakup. The circles denote the HALOE observations (tangent points) mapped to the same synoptic time.

ular at $585 \mathrm{~K}$ ). Consequently, the correlation coefficient $\rho$ between the HALOE observations and CLaMS simulations increases from 0.5 to 0.74 and from 0.38 to 0.64 for $\theta=450$ and $585 \mathrm{~K}$, respectively. The deviations still present at $585 \mathrm{~K}$ are mainly caused by the errors of the simulated absolute position of the vortex remnants. This indicates that the quality of the ECMWF winds is better at 450 than at $585 \mathrm{~K}$.

Thus, using 3-D trajectory calculations and by comparing CLaMS $\mathrm{CH}_{4}$ distributions with the HALOE observations, we conclude that isentropic transport dominated the propagation of the vortex air into the mid-latitudes several weeks before and after breakup of the vortex in 1997 and 2000. 


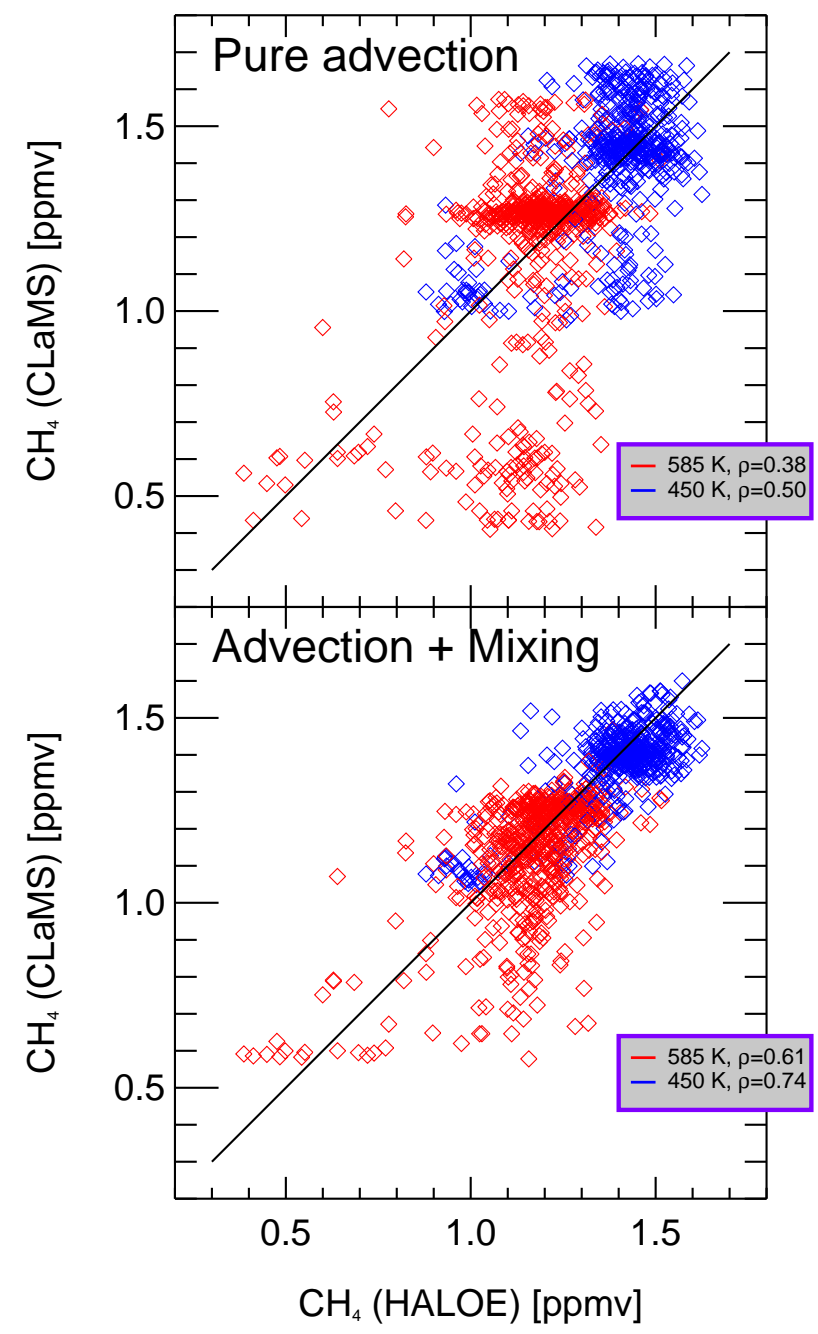

Fig. 2. CLaMS transport of $\mathrm{CH}_{4}$ versus HALOE observations northward of $30^{\circ} \mathrm{N}$ between 10 April and 31 June 1997 at $\theta=450$ and $\theta=585 \mathrm{~K}$ without mixing (upper panel) and with optimal mixing (lower panel).

\section{Spatial distribution and lifetime of vortex remnants in 1997 and 2000}

In 1997, the polar vortex was unusually long-lived (Coy et al., 1997). Even at the end of April, the vortex was very symmetrical around the pole and stable, and it did not break up until mid-May. On the other hand, the breakup of the vortex in 2000 was around mid-March, i.e. during a time period typical for the onset of the final warming in the northern hemisphere (Manney and Sabutis, 2000).

The zonal distribution of the vortex remnants after the vortex breakup is mainly determined by the isentropic winds. In Fig. 3 the zonal mean winds at 450 and $585 \mathrm{~K}$ are shown for both periods considered. Owing to the long vortex lifetime in 1997 , the vortex breakup at $585 \mathrm{~K}$ is accompanied by a transition from the winter to the summer circulation with no influence of the subtropical jet. On the other hand, the transport of vortex remnants at $450 \mathrm{~K}$ is driven by westerly winds and influenced by the subtropical jet. The zonally averaged winds in 2000 show a similar structure although a strong subtropical jet is present even in the upper level and the summer circulation is still not fully developed owing to the earlier breakup time.

By performing the CLaMS simulations, we now investigate the meridional distribution of the vortex air and the influence of mixing (i.e. of the irreversible part of transport) on such a distribution. CLaMS results for the zonally averaged meridional distribution of the vortex air after the vortex breakup in 1997 are shown in Fig. 4. Results at $450 \mathrm{~K}$ (left) and $585 \mathrm{~K}$ (right) are plotted for tracer transport without mixing (top) and with excessive mixing (bottom) corresponding to the mean distance between neighboring APs $r_{0}=200 \mathrm{~km}$. In the model, vortex air is defined as air masses bounded at the beginning of the simulation by the vortex edge identified by the strongest PV gradient with respect to equivalent latitude (Nash et al., 1996). To mark vortex air, an additional, artificial tracer is used and initialized as 1 and 0 within and outside of the vortex, respectively. The subsequent transport (advection + mixing) of this tracer describes the zonal distribution of the vortex air.

The comparison between top and bottom panels of Fig. 4 shows a negligible influence of mixing on the zonal distribution of the vortex air. Even for CLaMS simulations without mixing, the zonal averaging of the (unmixed) air parcels leads to a similar meridional distribution of the vortex air as in the case where mixing was exaggerated. Thus, the largescale meridional transport of vortex air into the mid-latitudes is dominated by the chaotic advection (induced e.g. by planetary waves) rather than by mixing. The zonally averaged tracks of vortex remnants (black lines in Figs. 4 and 3) show a stronger southward propagation at $585 \mathrm{~K}$ than at $450 \mathrm{~K}$. In agreement with the investigations of Piani et al. (2002), this propagation at $450 \mathrm{~K}$ is confined by the subtropical jet to latitudes poleward of $55^{\circ} \mathrm{N}$. The southward transport of vortex air at $585 \mathrm{~K}$ is more effective and reaches about $40^{\circ} \mathrm{N}$.

However, mixing may significantly influence the lifetime of vortex remnants, i.e., the time that is necessary to homogeneously mix vortex air with ambient air. The temporally and spatially inhomogeneous CLaMS mixing is driven by integral flow deformation that can be quantified in terms of the finite-time Lyapunov exponent $\lambda$.

Thus, CLaMS produces high mixing intensity only in flow regions with sufficiently high values of $\lambda$. Figure 5 shows the zonally averaged Lyapunov exponents $\lambda$ calculated for each CLaMS AP over a time step $\Delta t=12$ hours. After the vortex breakup, the summer circulation at $585 \mathrm{~K}$ is characterized by very low values of $\lambda$. Generally, the summer circulation in the middle stratosphere can be understood as a "solid body rotation" with a negligible amount of local strain between the neighboring APs (Piani and Norton, 2002). Consequently, the regridding algorithm in CLaMS that is driven 
1997
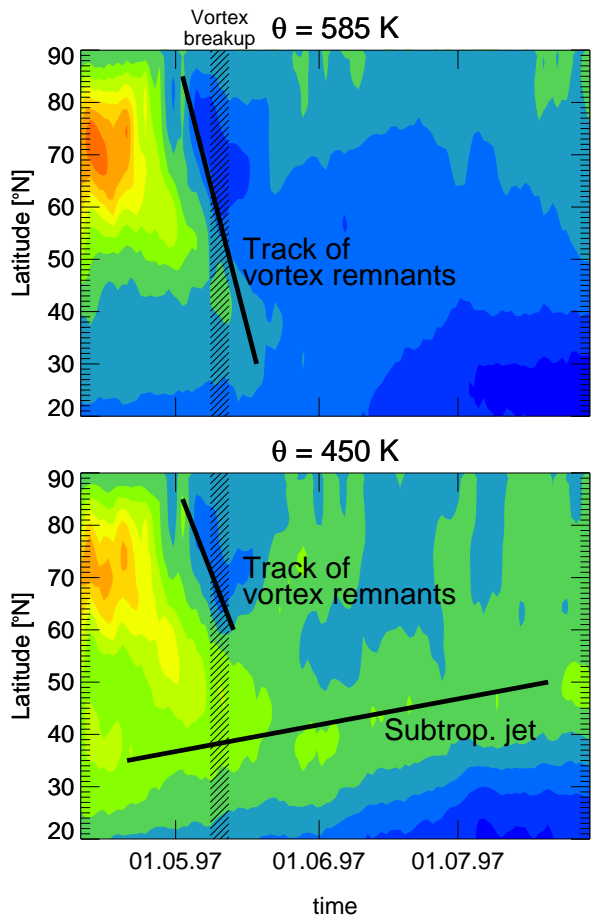

2000

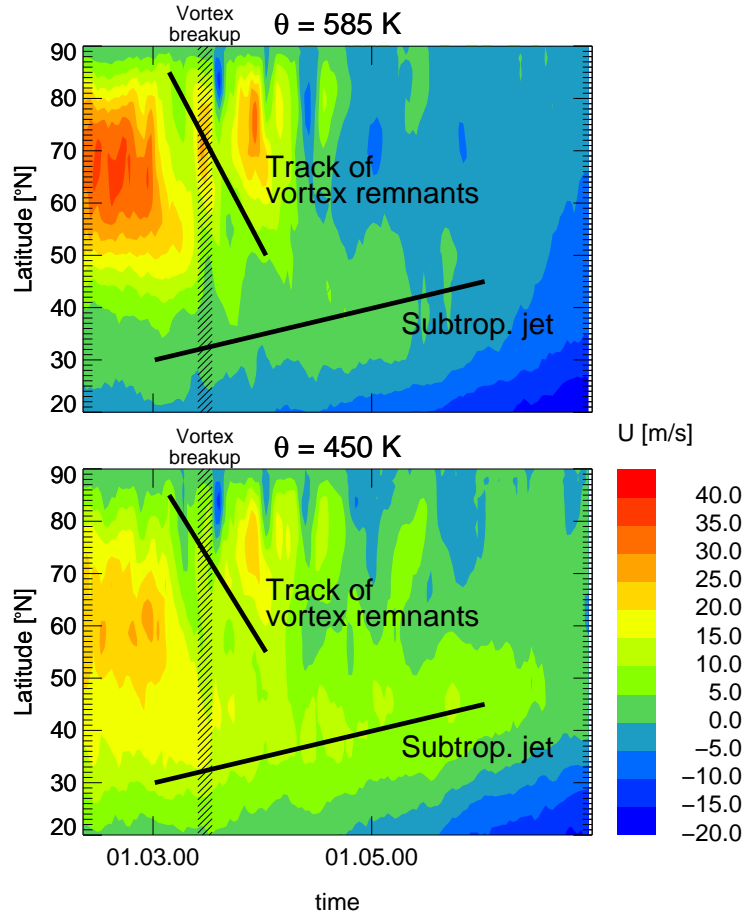

Fig. 3. Zonal mean ECMWF winds at $\theta=450$ (bottom panels) and $585 \mathrm{~K}$ (top panels) for the 1997 (left) and 2000 (right) period. The southward propagation of the vortex remnants is bounded by the subtropical jet. Their meridional tracks are derived from zonally averaged distribution of the vortex air (see Fig. 4).
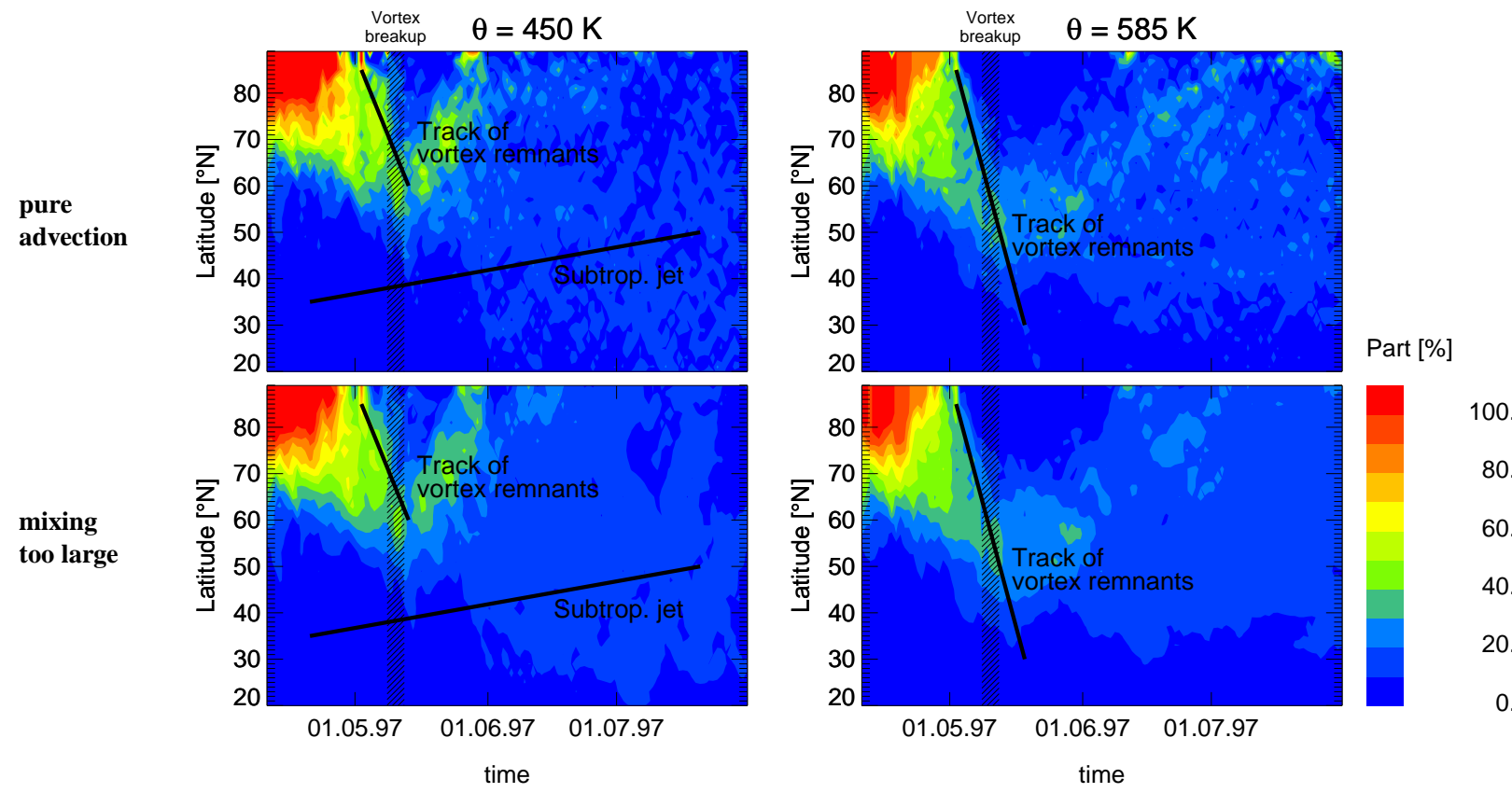

Fig. 4. Meridional (zonally averaged) contribution of vortex air at $\theta=450$ (left) and $585 \mathrm{~K}$ (right) for CLaMS simulation without (top) and with excessive (bottom) mixing. The colors denote the zonally averaged percentage of the vortex air changing from $100 \%$ (pure vortex air) to $0 \%$ (pure extra vortex air). The black lines denote the tracks of the vortex air masses during their transport into the mid-latitudes (see also Fig. 3) 


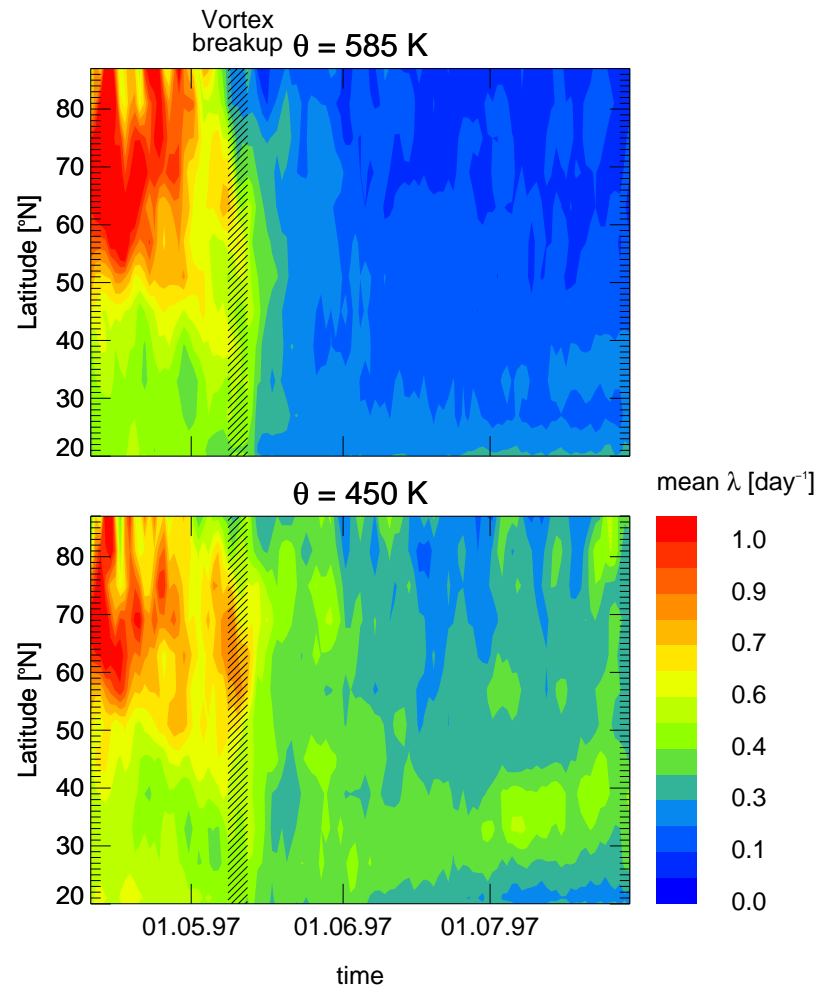

Fig. 5. Zonally averaged Lyapunov exponent $\lambda$ during the 1997 period calculated over a time step $\Delta t=12$ hours at $\theta=450$ and $585 \mathrm{~K}$. Note that the summer circulation at $585 \mathrm{~K}$ is characterized by very low values of $\lambda$.

by the local deformation rates, indicates very weak mixing at this level that is in agreement with the diagnostic of atmospheric transport in terms of the effective diffusivity (Haynes and Shuckburgh, 1999).

To quantify the effect of mixing on the lifetime of vortex remnants the PDFs (probability density function) calculated for $\mathrm{CLaMS} \mathrm{CH}_{4}$ distributions are shown in Fig. 6. The PDF is proportional to the area occupied by tracer values in a given range of mixing ratios (for details see e.g. Sparling, 2000). Here, the black lines denote the vortex edge transformed from the PV to $\mathrm{CH}_{4}$ field. Thus, the PDFs of the $\mathrm{CH}_{4}$ values below these lines describe the contribution of vortex air to all air masses poleward of $30^{\circ} \mathrm{N}$. The results show that the vortex remnants disappear significantly faster at 450 than at $585 \mathrm{~K}$. The greater Lyapunov exponents in the lower level cause more stirring, greater local deformation rates, and, consequently, more mixing. The lifetime of the vortex remnants at 450 and $585 \mathrm{~K}$ is of the order 5 and 10 weeks, respectively. The behavior of vortex remnants formed in March 2000 is similar but, due to an earlier vortex breakup, dominated until mid-May by westerly winds, even at $585 \mathrm{~K}$.

It should be emphasized that isentropic simulations may overestimate the lifetime of the vortex remnants, especially in the last phase of their existence when the remnants are los-

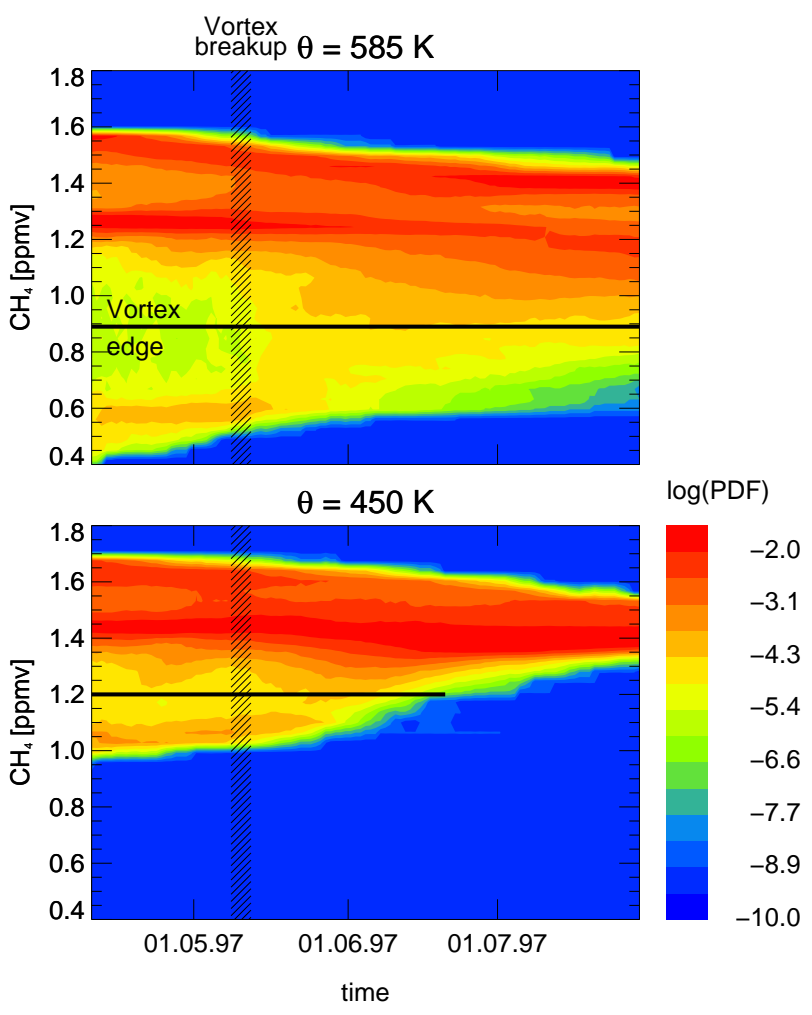

Fig. 6. PDF of $\mathrm{CH}_{4}$ at $\theta=450$ and $585 \mathrm{~K}$ calculated during the 1997 period. The black lines denote the mean $\mathrm{CH}_{4}$ at the vortex edge at the beginning of the simulation. The vortex edge was determined by using the Nash criterion (Nash et al., 1996).

ing their vertical coherence. Here, the vortex fragments may form elongated and slanted sheets of air, the so-called laminae (see e.g. Orsolini et al., 1995) with a very complicated contact surface separating the vortex from the mid-latitude air (Haynes and Anglade, 1997). Thus, although the isentropic 2-D simulations underestimate such contact surfaces and, consequently, overestimate the lifetime of the vortex remnants, the ratio of their lifetimes is a rather reliable quantity. We conclude that the lifetime of the remnants at $585 \mathrm{~K}$ is longer than at $450 \mathrm{~K}$ by a factor of 2 .

\section{Ozone chemistry in vortex remnants}

In the previous section, we showed that the vortex air trapped in the long-lived vortex remnants is well-isolated from the mid-latitudes. Here, we discuss some properties of the $\mathrm{O}_{3}$ chemistry observed and simulated in such remnants in spring/summer 1997 and 2000. It is a well-established fact that the polar $\mathrm{O}_{3}$ loss is due to halogen-catalyzed ozone loss with primary contributions of the reactive chlorine and bromine species which are activated heterogeneously on the surface of the polar stratospheric cloud particles, a primary component of which is nitric acid $\left(\mathrm{HNO}_{3}\right)$ (Solomon, 1999). 

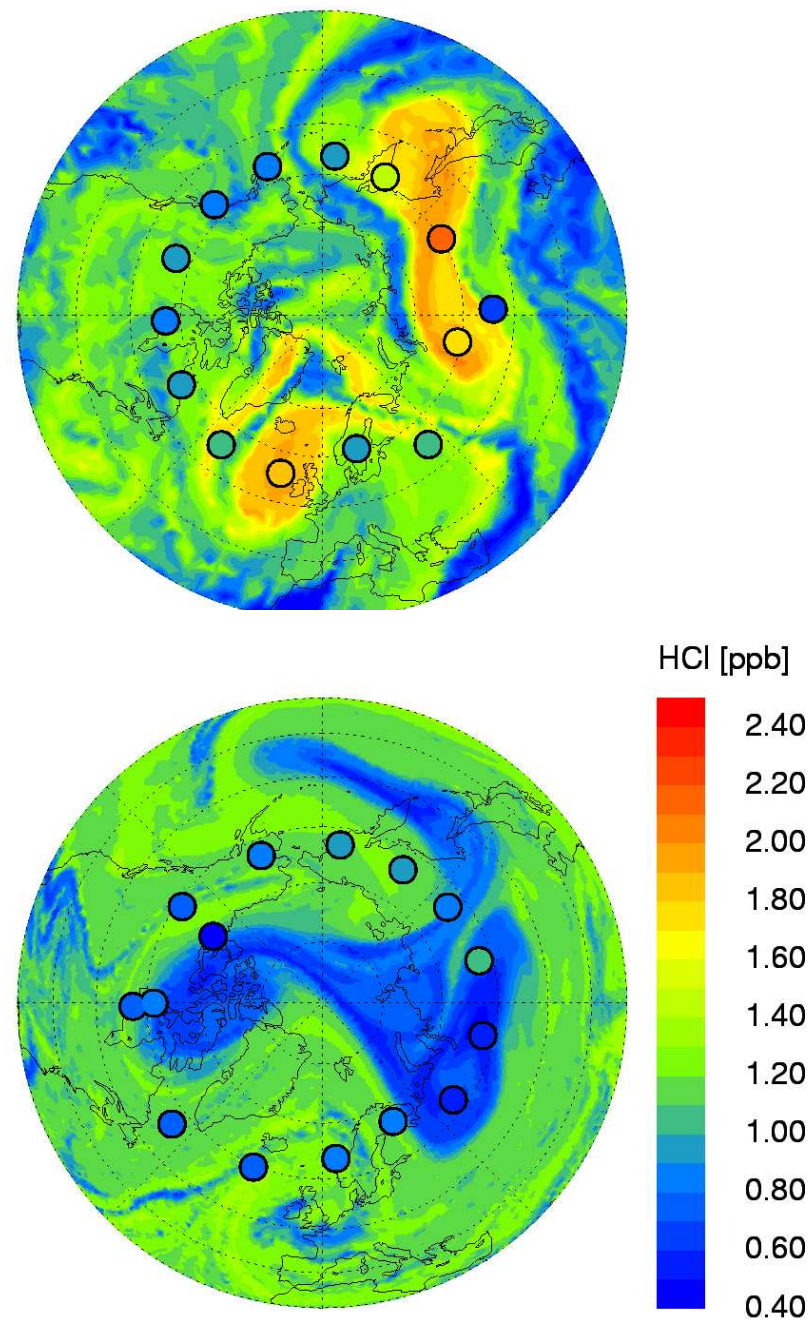

Fig. 7. $\mathrm{HCl}$ simulated with CLaMS at $\theta=450 \mathrm{~K} 2$ days after the vortex breakup at 12.05.1997 (top) and 17.03.2000 (bottom). High values of $\mathrm{HCl}$ indicate a completed chlorine deactivation. The circles denote the HALOE observations

Under Arctic conditions, the ozone loss terminates in spring, as chlorine is deactivated through the formation of $\mathrm{ClONO}_{2}$ and a subsequent transformation to $\mathrm{HCl}$ (Douglass et al., 1995). The main source of $\mathrm{NO}_{x}$ which controls the deactivation of $\mathrm{ClO}_{x}$ is either the photolysis of $\mathrm{HNO}_{3}$, its reaction with $\mathrm{OH}$, or its flux from mid-latitudes. During the period when $\mathrm{ClONO}_{2}$ is converted into $\mathrm{HCl}$, the photolytically or heterogenously induced reactivation of $\mathrm{ClO}_{x}$ from $\mathrm{ClONO}_{2}$ is still possible.

Thus on the one hand, the formation of $\mathrm{HCl}$ in the vortex air determines when the chlorine-induced $\mathrm{O}_{3}$ destruction is terminated. On the other hand, the breakup of the vortex defines when chaotic advection and intense mixing dominate the transport of vortex air into the mid-latitudes. Figure 7 shows the simulated $\mathrm{HCl}$ distributions (using the optimal mixing) two days after the vortex breakup in 1997 and 2000.

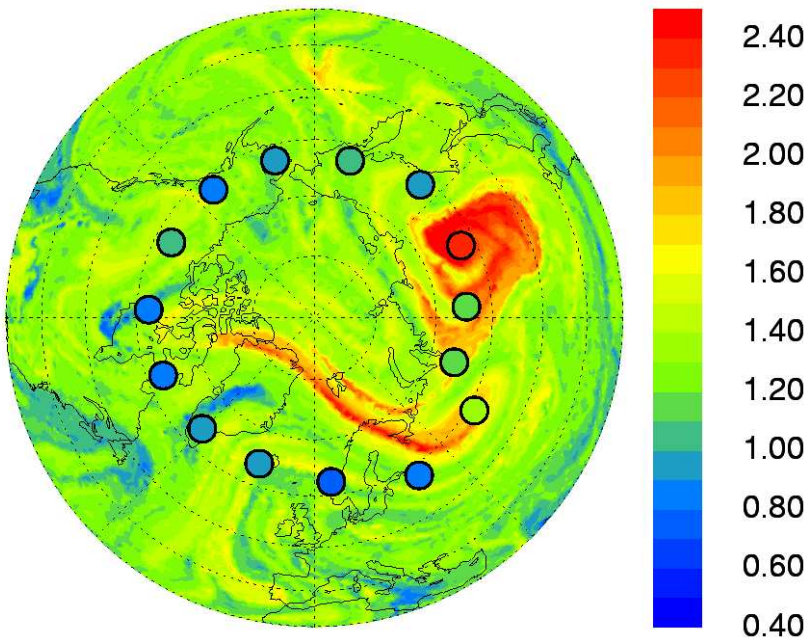

Fig. 8. $\mathrm{HCl}$ simulated with CLaMS at $\theta=450 \mathrm{~K}$ on 29.04 .2000 , i.e. 44 days after the vortex breakup.

The black circles denote the corresponding HALOE observations that in the vortex remnants agree fairly well with the CLaMS calculations. The high $\mathrm{HCl}$ mixing ratios that were observed in May 1997 indicate a completed chlorine deactivation whereas this process is still under way in March 2000. As can be seen in Fig. 8, first at the end of April (i.e. 44 days after the vortex breakup) significantly enhanced mixing ratios of $\mathrm{HCl}$ become apparent in the simulated vortex remnants that were also observed by HALOE (Müller et al., 2002).

A more quantitative description of the deactivation process is given in Fig. 9 where the mean $\mathrm{O}_{3}$ loss rate (per day) averaged over the vortex air together with the partitioning of $\mathrm{O}_{3}$ loss into different chemical destruction cycles are shown. To distinguish the vortex from the mid-latitude air, we use the transported (i.e. advected and mixed) PV fields. Then, the vortex air is defined as air masses with PV values larger than PV at the vortex edge (Nash et al., 1996) at the beginning of the simulation.

A comparison of the mean net $\mathrm{O}_{3}$ loss rate at $450 \mathrm{~K}$ during the time periods around the vortex breakup in 1997 and 2000 shows significantly faster $\mathrm{O}_{3}$ depletion in March 2000 than in May 1997. In particular, between the time of the vortex breakup around mid-March and mid-April 2000, the $\mathrm{O}_{3}$ destruction in the vortex remnants was still dominated by the halogen cycles (green line). By contrast, in mid-May 1997, these cycles are negligible, even shortly before the vortex breakup. As already mentioned, these differences can be explained by the fact that the chlorine deactivation due to formation of $\mathrm{HCl}$ is completed before the final vortex breakup in May 1997, whereas the formation of $\mathrm{HCl}$ in spring 2000 is finished in the vortex remnants in mid-April. 
1997

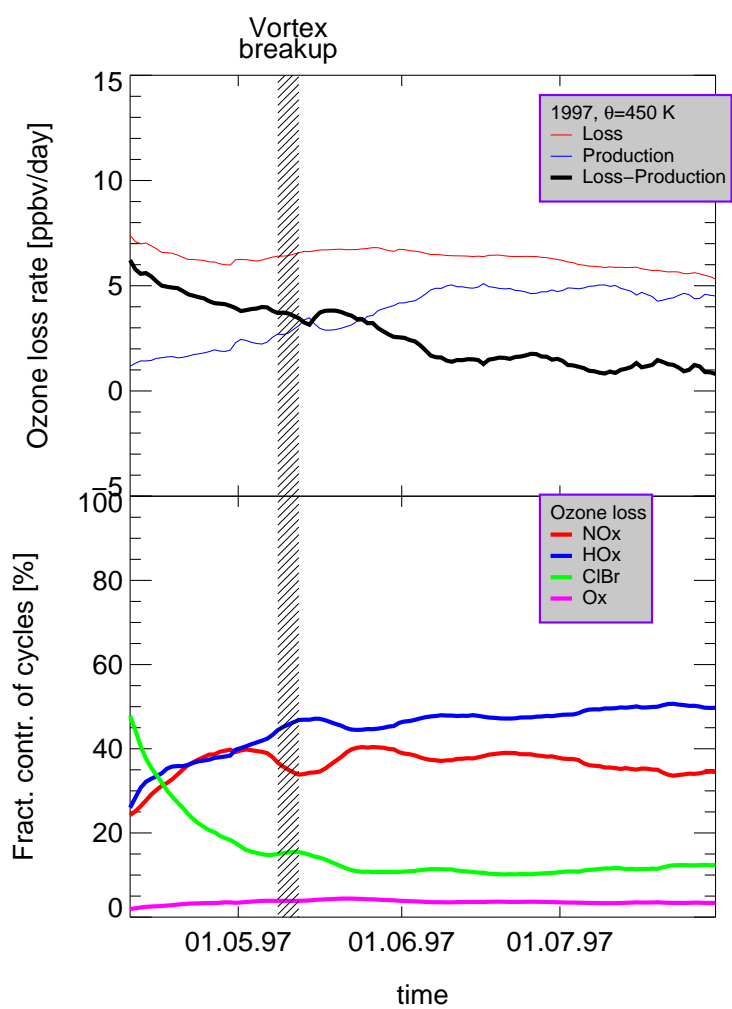

2000

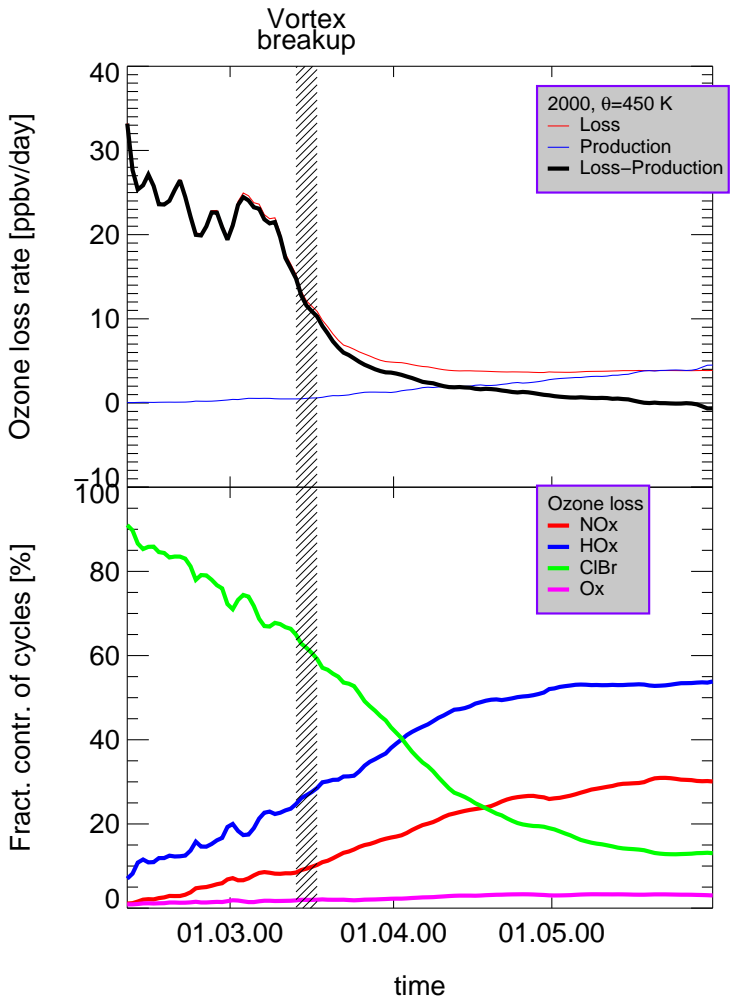

Fig. 9. Top: Mean ozone loss rate (per day) in the vortex air (i.e. air masses with transported PV larger than vortex edge PV at the beginning of the simulation). Bottom: Contribution of different chemical destruction cycles at $450 \mathrm{~K}$ in 1997 (left) and 2000 (right).

At $450 \mathrm{~K}$ the contribution of $\mathrm{HO}_{x}\left(\mathrm{HO}_{x}=\mathrm{HO}_{2}+\mathrm{OH}\right)$ outweighs the $\mathrm{NO}_{x}$-induced ozone destruction and is dominated by the direct reaction of $\mathrm{HO}_{x}$ with ozone. Here, the ozone destruction driven by $\mathrm{NO}_{x}$ formed by the photolytical decomposition of $\mathrm{ClONO}_{2}$ (Toumi et al., 1993) is classified as $\mathrm{NO}_{x}$-induced ozone destruction and contributes up to $45 \%$ to the $\mathrm{NO}_{x}$-cycles around mid-April (not shown in Fig. 9).

A similar analysis of the $\mathrm{O}_{3}$ chemistry in the long-lived vortex remnants at $585 \mathrm{~K}$ in 1997 shows that the most important destruction cycle is the "summertime" $\mathrm{NO}_{x}$ chemistry (Hansen and Chipperfield, 1999; Fahey and Ravishankara, 1999). Furthermore, the fractional contribution of the different cycles to the $\mathrm{O}_{3}$ loss in the vortex remnants does not significantly differ from the $\mathrm{O}_{3}$ loss partitioning calculated for extra-vortex air masses northward of $60^{\circ} \mathrm{N}$ (not shown). Although the chemical composition of the coarsely-mixed vortex remnants still differs from the composition of the ambient air, the contribution of the $\mathrm{O}_{3}$ loss cycles to the total $\mathrm{O}_{3}$ depletion is very similar in both types of air.

The fact that the deactivation process in spring 1997 was still completed in a well-isolated vortex indicates that, at least in this year, the chlorine deactivation was decoupled from mixing and mainly driven by the in situ chemical production of $\mathrm{NO}_{x}$. On the other hand, the incomplete deactivation shortly before the vortex breakup in March 2000 offers the possibility of studying the influence of mixing on this process during the final vortex decay.

\section{The impact of mixing}

Using different values of the mixing parameters, we now study the influence of mixing on the accumulated ozone loss in the mid and high latitudes after the vortex breakup around mid-March 2000 at the isentropic surface $450 \mathrm{~K}$. The accumulated ozone loss is defined as the difference between the passively transported and chemically changed ozone. Here, this difference is determined for the time period between 10.02 and 31.05.2000 and averaged over all air masses poleward of $30^{\circ} \mathrm{N}$. The results calculated for the optimal mixing are shown in Fig. 10 (red line).

In order to study the influence of halogen chemistry on the $\mathrm{O}_{3}$ loss, the black line describes the accumulated ozone loss calculated from a chemistry run without halogen cycles $\left(\mathrm{Cl}_{y}=\mathrm{Br}_{y}=0\right)$. The yellow curve describes the accumulated ozone loss for a scenario with a strong denitrification as would be expected for Antarctic conditions $\left(\mathrm{HNO}_{3} \approx 2 \mathrm{ppbv}\right.$ in the vortex). The remaining curves describe the sensitivity 


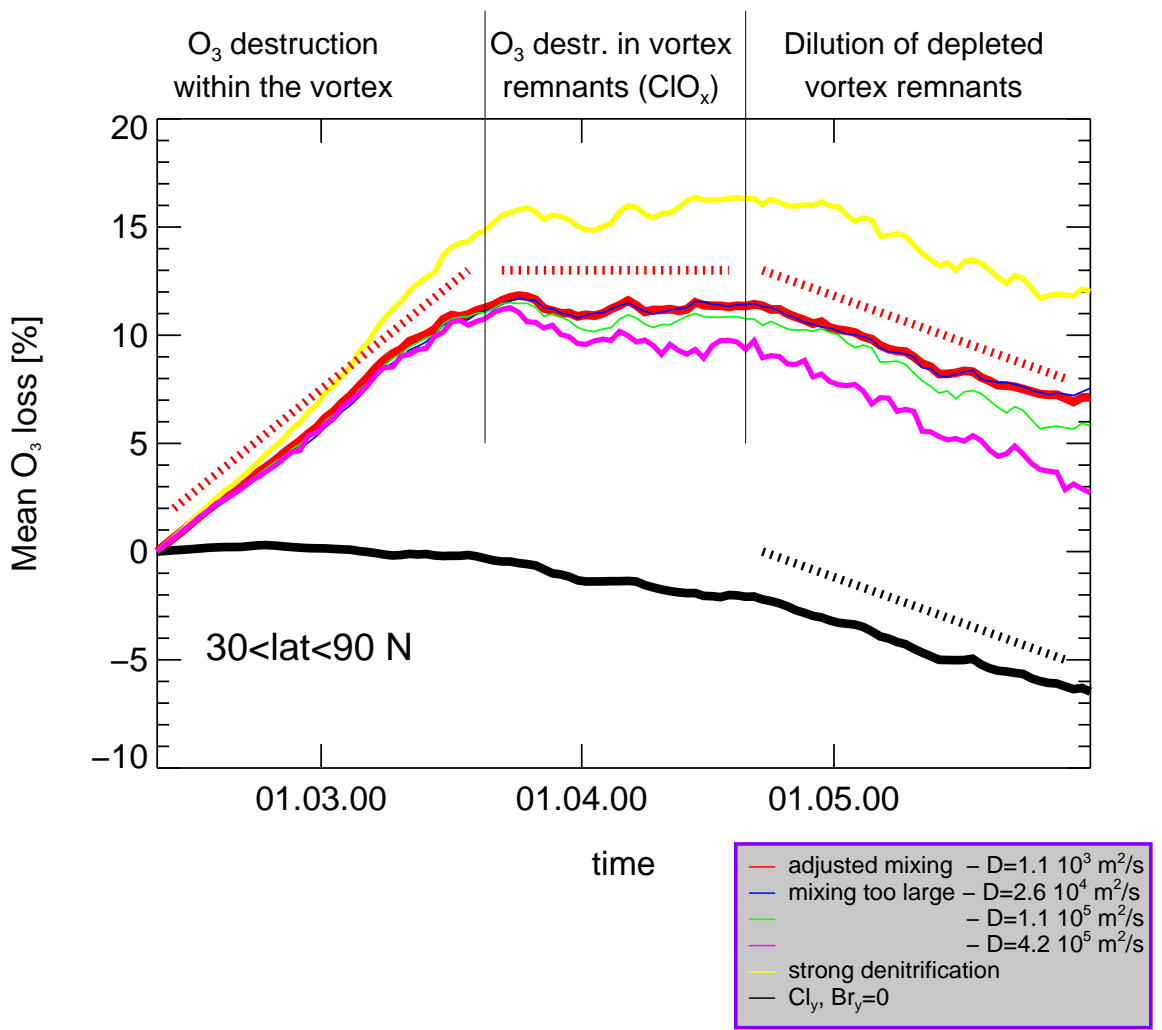

Fig. 10. Accumulated ozone loss poleward of $30^{\circ} \mathrm{N}$ at $450 \mathrm{~K}$ (red line). The black line describes the accumulated ozone loss calculated from a chemistry run without halogen cycles $\left(\mathrm{Cl}_{y}=\mathrm{Br}_{y}=0\right)$. The remaining solid lines are explained in the text. The dashed lines define 3 periods with respect to the following effects in the ozone chemistry: $\mathrm{O}_{3}$ destruction within the vortex, $\mathrm{O}_{3}$ destruction in vortex remnants and dilution of depleted vortex remnants. During the last period, the reference run (red) and the halogen-free atmosphere (black) show the same mean ozone loss.

of the reference simulation (red) on the intensity of mixing with effective diffusivity varying between $1.110^{3}$ and 4.2 $10^{5} \mathrm{~m}^{2} \mathrm{~s}^{-1}$

Thus, the halogen-induced mid-latitude ozone deficit in spring 2000, defined here as the difference between the red and black curves, can be divided into 3 phases (see dashed red and black lines in Fig. 10). Until mid-March ozone destruction due to halogen chemistry occurs in a well-isolated Arctic vortex. From mid-March (vortex breakup) until midApril the ozone-depleted air masses are transported into the mid-latitudes. By comparing the slopes of the red and black lines during this period, we conclude that the chlorine and bromine chemistry still destroy ozone in vortex remnants (see Fig. 9), albeit with a smaller intensity than in February and in early March. Here, the main source of active chlorine is the photolysis of $\mathrm{ClONO}_{2}$. Between mid-April and end of May, the slopes of the dashed black and red lines are comparable and, consequently, the halogen-induced ozone destruction is negligible during this period. Thus, compared with the ozone distribution in a halogen-free stratosphere (black line), the mid-latitude ozone deficit at the isentropic level $450 \mathrm{~K}$ can be determined. Thus, the halogen-induced ozone deficit at the end of May amounts to about $12 \%$. The contribution of the vortex remnants formed after the vortex breakup can be quantified to about $2 \%$.

The sensitivity studies with respect to mixing show that the accumulated ozone loss does not change as long as the effective diffusivity in the model is smaller than $3 \times 10^{4}$ $\mathrm{m}^{2} / \mathrm{s}$. This value corresponds to a spatial resolution of the order $100 \mathrm{~km}$. Also, the deactivation of $\mathrm{ClO}_{x}$ via formation of $\mathrm{ClONO}_{2}$ is mainly due to photochemical decomposition of $\mathrm{HNO}_{3}$ rather than to chemistry induced by mixing of the activated vortex air with $\mathrm{NO}_{x}$-rich mid-latitude air. Only if diffusion is greater than an unrealistically large critical value of $10^{5} \mathrm{~m}^{2} / \mathrm{s}$ (corresponding to a spatial resolution of the order $200 \mathrm{~km}$ ) mixing of mid-latitude air has a significant impact on $\mathrm{ClONO}_{2}$ formation in vortex remnants.

Using an Eulerian model, Tan et al. (1998) postulated a much stronger influence of the numerical mixing on the chlorine deactivation. They concluded that Eulerian grid resolution better than $40 \mathrm{~km}$ is necessary to correctly describe the deactivation process. Assuming that the numerical diffusivity is proportional to $r_{0}^{2} / \Delta t$, the discussed Lagrangian critical resolution $r_{0 L}=r_{0} \approx 100 \mathrm{~km}$ can be transformed to an equivalent Eulerian resolution $r_{0 E}$ by $r_{0 E}=r_{0 L} \sqrt{\Delta t_{E} / \Delta t_{L}}$ where $\Delta t_{L} \approx 24$ hours and $\Delta t_{E} \approx 15 \mathrm{~min}$ are the typical 
Lagrangian and Eulerian time steps. Using this crude estimate, we obtain $r_{0 E} \approx 10 \mathrm{~km}$ that probably underestimates the critical resolution of the Eulerian schemes discussed by Tan et al. (1998) (the difference between the 10 and $40 \mathrm{~km}$ is probably due to the weak diffusivity of the Prather scheme). Nevertheless, the small numerical diffusion of the Lagrangian transport allows the mixing-sensitive processes to be studied by using model resolutions that are coarser than the corresponding Eulerian studies.

In addition, our studies show that mixing may influence chemistry in some small-scale filaments during their final dissipation. For budget studies (e.g. impact of mixing on the mid-latitude ozone deficit) such small-scale structures are negligible if compared with large, coherent vortex fragments where the bulk contribution outweighs the effect of the mixing-sensitive surface. Thus, even after the vortex breakup in mid-March 2000, the averaged deactivation process is dominated by in situ chemistry rather than mixing. Furthermore, the results of pure advection studies (i.e. in terms of the photochemical box model) do not significantly differ from the simulations with the optimal mixing. One reason for this weak impact of mixing on the $\mathrm{O}_{3}$ chemistry may be the fact that shortly before the vortex breakup a significant amount of active chlorine was transformed into $\mathrm{ClONO}_{2}$. If strong intrusions of the mid-latitude air occur into a vortex with chlorine fully activated (as discussed e.g. in Plumb et al., 1994), the importance of mixing on the deactivation process may be higher.

\section{Conclusions}

Full chemistry simulations were carried out with the Chemical Lagrangian Model of the Stratosphere (CLaMS) to study the spatial distribution, lifetime and $\mathrm{O}_{3}$ chemistry of the vortex remnants created after the vortex breakup in spring and summer 1997 and 2000. Isentropic 2-D simulations on two isentropic levels $450 \mathrm{~K}(\approx 18 \mathrm{~km})$ and $585 \mathrm{~K}(\approx 24 \mathrm{~km})$ were conducted with a very high spatial resolution (up to $20 \mathrm{~km}$ ) in order to resolve the filamentary structure of slowly dissipating vortex remnants. The isentropic approximation was justified by the comparison with the HALOE tracer measurements and radiation calculations.

In agreement with the investigations of Orsolini (2001) and Piani et al. (2002), the zonal distribution of the vortex air after the vortex breakup shows different patterns above and belove $20 \mathrm{~km}$. Especially in summer 1997, the differences are evident with long-lived vortex remnants above $20 \mathrm{~km}$, which are trapped in the "solid body" summer circulation with very weak mixing, and, below $20 \mathrm{~km}$, with a significant stirring and mixing caused by the influence of the subtropical jet. The subtropical jet bounds the southward propagation of the remnants up to $55^{\circ} \mathrm{N}$ below $20 \mathrm{~km}$ whereas above $20 \mathrm{~km}$ the weakly mixed vortex air may reach $40^{\circ} \mathrm{N}$. Although the meridional distribution of such remnants is mainly deter- mined by the chaotic advection, their lifetime, in contrast, strongly depends on mixing and above $20 \mathrm{~km}$ it is approximately twice as long as below $20 \mathrm{~km}$. The isentropic simulations may underestimate mixing and, consequently, the absolute lifetimes of the vortex remnants, in particular during the phase when the vortex remnants lose their vertical coherence.

The different times of vortex breakup in 1997 and 2000 are responsible for different chemical signatures in vortex remnants simulated with CLaMS and observed by HALOE. The $\mathrm{O}_{3}$ chemistry in the vortex remnants strongly depends on the partitioning between active and reservoir compounds within the $\mathrm{Cl}_{y}$ and $\mathrm{Br}_{y}$ families. If shortly before the vortex breakup, most of the chlorine is contained in $\mathrm{HCl}$ (as in 1997) then small ozone loss rates have to be expected in the vortex remnants, which are mainly driven by the $\mathrm{HO}_{x}(450 \mathrm{~K})$ and $\mathrm{NO}_{x}(585 \mathrm{~K})$ destruction cycles. If, on the other hand, $\mathrm{ClONO}_{2}$ and partially $\mathrm{ClO}_{x}$ are the main reservoirs of the chlorine shortly before the vortex breakup (as in 2000), then a chlorine-induced ozone destruction within the vortex remnants can be expected mainly due the photolytical decomposition of $\mathrm{ClONO}_{2}$. The impact of mixing is negligible due to a negligible flux of $\mathrm{NO}_{x}$ into the (coherent) vortex remnants. Here, the more important source of $\mathrm{NO}_{x}$ is the photolytical decomposition of $\mathrm{HNO}_{3}$.

For both investigated periods the simulated $\mathrm{O}_{3}$ loss in the vortex remnants is dominated by the in situ chemistry in the Lagrangian air parcels rather than by mixing between these air parcels and the mid-latitude air. The sensitivity studies with respect to mixing show that the accumulated ozone loss does not change as long as the effective diffusivity in the model is smaller than $10^{4} \mathrm{~m}^{2} / \mathrm{s}$, that is if the (Lagrangian) model resolution is better than $100 \mathrm{~km}$.

Acknowledgements. The European Centre for Medium-Range Weather Forecasts (ECMWF) and the United Kingdom Meteorological Office (UKMO) are acknowledged for meteorological data support. This work was funded by the European Union under contract numbers EVK2-1999-00311 (EU THESEO 2000) and EVK2CT-1999-000049 (SAMMOA)

\section{References}

Andersen, S. B. and Knudsen, B. M.: The influence of vortex ozone depletion on Arctic ozone trends, Geophys. Res. Lett., 29, 10.1029/2001GL014 595, 2002.

Balluch, M. G. and Haynes, P. H.: Quantification of lower stratospheric mixing processes using aircraft data, J. Geophys. Res. 102, 23 487-23 504, 1997.

Chipperfield, M. P. and Jones, R. L.: Relative influences of atmospheric chemistry and transport on arctic ozone trends, Nature, 400, 551-554, 1999.

Coy, L., Nash, E., and Newman, P.: Meteorology of the polar vortex: Spring 1997, Geophys. Res. Lett., 24, 2693-2696, 1997.

Douglass, A. R., Schoeberl, M. R., Stolarski, R. S., Waters, J. W., Russell III, J. M., Roche, A. E., and Massie, S. T.: Interhemispheric differences in springtime production of $\mathrm{HCl}$ and $\mathrm{ClONO}_{2}$ in the polar vortices, J. Geophys. Res., 100, 13 967-13 978, 1995. 
Edouard, S., Legras, B., Lefèvre, F., and Eymard, R.: The effect of small-scale inhomogeneities on ozone depletion in the Arctic, Nature, 384, 444-447, 1996.

Fahey, D. and Ravishankara, A.: Summer in the stratosphere, Science, 285, 208-210, 1999.

Grooß, J.-U., Günther, G., Konopka, P., Müller, R., McKenna, D. S., Stroh, F., Vogel, B., Engel, A., Müller, M., Hoppel, K., Bevilacqua, R., Richard, E., Webster, C. R., Elkins, J. W., Hurst, D., Romashkin, P. A., and Baumgardner, D. G.: Simulation of ozone depletion in spring 2000 with the Chemical Lagrangian Model of the Stratosphere (CLaMS), J. Geophys. Res., 107, 8295, doi:10.1029/2001JD000 456, 2002.

Hansen, G. and Chipperfield, M. P.: Ozone depletion at the edge of the Arctic polar vortex 1996/1997, J. Geophys. Res., 104, 1837$1845,1999$.

Haynes, P. and Anglade, J.: The vertical scale cascade in atmospheric tracers due to large-scale differential advection, J. Atmos. Sci., 54, 1121-1136, 1997.

Haynes, P. and Shuckburgh, E.: Effective diffusivity as a diagnostic of atmospheric transport. Part I: Stratosphere, J. Geophys. Res., 105, 22 777-22 794, 2000.

Hess, P.: Mixing processes following the final stratospheric warming, J. Atmos. Sci., 42, 1625-1641, 1991.

Knudsen, B. M. and Grooß, J. U.: Northern midlatitude stratospheric ozone dilution in spring modeled with simulated mixing, J. Geophys. Res., 105, 6885-6890, 2000.

Konopka, P., Grooß, J. U., Günther, G., McKenna, D. S., Müller, R., Elkins, J. W., Fahey, D., Popp, P., and Stimpfle, R. M.: Weak influence of mixing on the chlorine deactivation during SOLVE/THESEO2000: Lagrangian modeling (CLaMS) versus ER-2 in situ observations., J. Geophys. Res., 108, 10.1029/2001JD000 876, 2003.

Manney, G. L. and Sabutis, J. L.: Development of the polar vortex in the 1999-2000 Arctic winter stratosphere, Geophys. Res. Lett., 27, 2589-2592, 2000.

Marchand, M., Godin, S., Hauchecorne, A., Lefèvre, F., and Bekki, S.: Influence of polar ozone loss on Northern midlatitude regions estimated by a high resolution chemistry transport model during winter 1999-2000, J. Geophys. Res., 108, 10.1029/2001JD000 906, 2003.

McKenna, D. S., Grooß, J.-U., Günther, G., Konopka, P., Müller, R., Carver, G., and Sasano, Y.: A new Chemical Lagrangian Model of the Stratosphere (CLaMS): Part II Formulation of chemistry-scheme and initialisation, J. Geophys. Res., 107, 10.1029/2000JD000 113, 2002a.

McKenna, D. S., Konopka, P., Grooß, J.-U., Günther, G., Müller, R., Spang, R., Offermann, D., and Orsolini, Y.: A new Chemical Lagrangian Model of the Stratosphere (CLaMS): Part I Formulation of advection and mixing, J. Geophys. Res., 107, 10.1029/2000JD000 114, 2002b

Morcrette, J.-J.: Radiation and cloud radiative properties in the European Centre for Medium-Range Weather Forecasts forecasting system, J. Geophys. Res., 96, 9121-9132, 1991.

Müller, R., Tilmes, S., Grooß, J.-U., McKenna, D. S., Müller, M., Schmidt, U., Toon, G. C., Stachnik, R. A., Margitan, J. J., Elkins, J. W., Arvelius, J., and III, J. M. R.: Chlorine activation and chemical ozone loss deduced from HALOE and balloon measurements in the Arctic during the winter of 1999-2000, J. Geophys. Res., 107, 8302, doi:10.1029/2001JD001 423, 2002.
Nash, E. R., Newman, P. A., Rosenfield, J. E., and Schoeberl, M. R.: An objective determination of the polar vortex using Ertel's potential vorticity, J. Geophys. Res., 101, 9471-9478, 1996.

Orsolini, Y., Simon, P., and Cariolle, D.: Filamentation and layering of an idealized tracer by observed winds in the lower stratosphere, Geophys. Res. Lett., 22, 839-842, 1995.

Orsolini, Y. J.: Long-lived tracer patterns in the summer polar stratosphere, Geophys. Res. Lett., 28, 3855-3858, 2001.

Orsolini, Y. J., Hansen, G., Hoppe, U. P., Manney, G. L., and Fricke, K. H.: Dynamical modelling of wintertime lidar observations in the Arctic, Q. J. R. Meteorol. Soc., 123, 785-800, 1997.

Piani, C. and Norton, W. A.: Solid-body rotation in the northern summer stratosphere, Geophys. Res. Lett., 29, 10.1029/2002GL016 079, 2002.

Piani, C., Norton, W. A., Iwi, A. M., Ray, E. A., and Elkins, J. W. Transport of ozone-depleted air on the breakup of the stratospheric polar vortex in spring/summer 2000, J. Geophys. Res., 107, 10.1029/2001JD000 488, 2002.

Plumb, R. A., Waugh, D. W., Atkinson, R. J., Newman, P. A., Lait, L. R., Schoeberl, M. R., Browell, E. V., Simmons, A. J., and Loewenstein, M.: Intrusions into the lower stratospheric Arctic vortex during the winter of 1991-1992, J. Geophys. Res., 99, 1089-1105, 1994.

Riese, M., Tie, X., Brasseur, G., and Offermann, D.: Threedimensional simulation of stratospheric trace gas distributions measured by CRISTA, J. Geophys. Res., 104, 16419-16435, 1999.

Searle, K. R., Chipperfield, M. P., Bekki, S., and Pyle, J. A.: The impact of spatial averaging on calculated polar ozone loss: I. Model experiments, J. Geophys. Res., 103, 25 397-25 408, 1998a.

Searle, K. R., Chipperfield, M. P., Bekki, S., and Pyle, J. A.: The impact of spatial averaging on calculated polar ozone loss: II. Theoretical analysis, J. Geophys. Res., 103, 25 409-25 416, 1998 b.

Solomon, S.: Stratospheric ozone depletion: A review of concepts and history, Rev. of Geophys., 37, 275-316, 1999.

Sparling, L. C.: Statistical perspectives on stratospheric transport, Rev. Geophys., 38, 417-436, 2000.

Tan, D. G. H., Haynes, P. H., MacKenzie, A. R., and Pyle, J. A.: Effects of fluid-dynamical stirring and mixing on the deactivation of stratospheric chlorine, J. Geophys. Res., 103, 1585-1605, 1998.

Toumi, R., Jones, R. L., and Pyle, J. A.: Stratospheric ozone depletion by $\mathrm{ClONO}_{2}$ photolysis, Nature, 365, 37-39, 1993.

Tuck, A. F.: Synoptic and chemical evolution of the Antarctic vortex in late winter and early spring, 1987, J. Geophys. Res., 94, $11,687-11,737,1989$

Waugh, D. W., Plumb, R. A., Elkins, J. W., Fahey, D. W., Boering, K. A., Dutton, G. S., Volk, C. M., Keim, E., Gao, R.-S., Daube, B. C., Wofsy, S. C., Loewenstein, M., Podolske, J. R., Chan, K. R., Proffitt, M. H., Kelly, K. K., Newman, P. A., and Lait, L. R.: Mixing of polar vortex air into middle latitudes as revealed by tracer-tracer scatterplots, J. Geophys. Res., 102, 13 119-13 134, 1997.

WMO: Scientific assessment of ozone depletion: 1998, Report No. 44, Geneva, 1998.

Zhong, W. and Haigh, J. D.: Improved broadband emissivity parameterization for water vapor cooling rate calculations, J. Atmos. Sci., 52, 124-138, 1995 